Virtual Mentor. February 2004, Volume 6, Number 2.

doi: 10.1001/virtualmentor.2004.6.2.pfor1-0402

Policy Forum

\title{
Addressing Paternalism with Patients' Rights: Unintended Consequences
}

\section{A bioethicist discusses how the need for patient autonomy and patients' rights can be fulfilled through strong patient-physician communication.}

Felicia Cohn, $\mathrm{PhD}$

Patients' rights statements, whether legislative proposals or institutional policies, are generally designed to protect and empower patients in the health care setting. They have arisen in response to paternalistic clinician behaviors, managed care disparities, and the technological imperative (ie, the belief that if we have the technology, we will use it). They seek to assure patient participation in and ultimate authority over decisions about medical care and to provide recourse if care does not go well.

This simplistic explanation of patients' rights suggests an appropriate emphasis on patient self-determination over conceptions of medical benefit with which the patient does not agree. Yet, the focus on rights language appears not to have produced a balance between the values of patient autonomy and physician beneficence; rather, rights language prioritizes autonomy over all other values, sometimes without adequate ethical justification. Patients' rights intended to enhance the patient-physician relationship can endanger the notion of relationship and reduce physicians to defensive technicians.

\section{Rights Versus Relationships}

The essence of the medical relationship is communication between patient and physician. By communicating, the patient and physician can determine together how best to treat the patient in accord with the patient's values and perception of his or her best medical interests, on the one hand, and the physician's professional knowledge, experience, and values, on the other. The American Medical Association describes the clinical encounter as the "embodiment" of medical practice and notes that it has "long been recognized that successful medical care requires an ongoing collaborative effort between patients and physicians" [1].

Yet, communication may be at the root of some of the problems in medicine that are triggering the call for explicit patients' rights. "What has been true for the evolution of mankind has been equally true for the progress of medicine: We have spared no effort to make better tools but we have paid little attention to learning how to communicate better with one another" [2]. A seminal study of end-of-life care, the "Study to Understand Prognoses and Preferences for Outcomes and Risks of Treatments (SUPPORT)", suggests a general failure in communication in the face of entrenched practice patterns. The study documents limited patient-physician communication occurring even after the implementation of measures to improve it [3-4]. The SUPPORT study demonstrated, for example, no change in the number of days patients remained in intensive care and no decrease in pain suffered, despite known patient wishes for less care and better pain management. If dialogue serves as the foundation of medical relationships, then:

Ideally, physicians should define their diagnostic and therapeutic goals in terms of the everyday life and function of individual patients. Unfortunately, that ideal is seldom met because of the difficulty of holding impersonal technical imperatives in check, and because doctors seem to be trained to focus on diseases almost to the exclusion of how sick persons actually live their lives in families and communities. In part 
the problem arises because physicians are trained from the first days of medical school to disregard the knowledge they bring with them of everyday life and human function as irrelevant to medicine. Another obstacle is that doctors are not trained to include in their decision making the kind of "soft" and often subjective information that is relevant to the everyday life and function of sick persons. Correction of these educational errors would do much to help change physician's priorities in patient care [5].

Such a change in physician priorities might quiet the cries for patients' rights and would reflect long-standing statements of medical values expressed in codes of ethics.

Patient advocates, seeking a means of correcting the inadequacies described, turn to the lever of the law. If we required physicians to provide patients with a role in clinical decision making, then collaboration, not conflict, would result. The majority of explicit patients' rights in existing bills and policies appear to be responses to inadequate or inappropriate communication. Studies, for example, suggest that even in the most egregious of medical errors, the harmed patients or their families were most aggrieved, not by the unfavorable medical outcome itself, but by the lack of disclosure or explanation or by the simple failure to apologize [6-7]. These sought-after rights really require only that patients be heard or allowed to have some measure of control over the information shared, eg, the right to refuse treatment, to lodge complaints, to maintain privacy and confidentiality.

Resorting to rights language as a solution for patient grievances, however, may be as much a problem as a solution. Rights language is notable for "its starkness and simplicity, its prodigality in bestowing the rights label, its legalistic character, its exaggerated absoluteness, its hyperindividualism, its insularity, and its silence with respect to personal, civic, and collective responsibilities" [8]. Rights are established to protect values that are fundamental to relationships, and when we are unable to establish those relationships, we turn to legislated solutions to enforce what is missing. Concepts of confidentiality, fairness, mutual respect, and compassion have long been part of the codes of medical practice. The need to develop policies and laws that speak to these values reflects not the need for rights but the lack of emphasis on the fundamental nature of the relationship in the context of health care. Legislating on these issues may ironically result in reducing the patient-physician encounter from a humanistic interaction to a legalistic contractual one, limiting rather than expanding expression of the very values the policies and laws were created to enhance.

\section{Physician as Technician}

Various metaphors and models exist to describe the role of the physician in a patient's life-such as parent, educator, counselor, priest, and negotiator [9-10]. Each metaphor highlights particular core values upon which the ethical practice of medicine is founded. These values arise "from the moral traditions of medicine and nursing and from the ethical, religious, and legal traditions of our society" and include beneficence (promotion of the patient's well-being); respect for patient autonomy (claim to decision making in medical care, including the patient's claim to selfgovernance); integrity of health care professionals (fidelity to one's own conscientious moral and religious beliefs); and justice (equitable distribution of health care resources) [11]. The parent-child or paternalistic model, for example, emphasizes beneficence and clinician integrity while the technician-consumer model emphasizes patient autonomy.

As patients' rights grow and the environment becomes more litigious, the technician metaphor may appear increasingly attractive. The technician-doctor, like the auto mechanic, assesses the problem, provides choices among available options, and is obligated to provide the treatment the patient selects; whereas the paternalistic doctor limits choice by selecting what he or she believes is the best treatment for the patient. In the climate of patients' rights, either failing to offer all that is technically available or imposing 1 option over another may become grounds for legal action, particularly if the course of care does not go well.

In prioritizing patient autonomy above all other values, however, the technician model fails to adequately account for the physician's moral agency and other values important to the practice of medicine. Further, the conception of autonomy that has come to guide medical interactions does not accurately reflect the meaning and limits of selfgovernance. Respect for patient autonomy refers to patient self-governance (shared decision making) and appreciating individual preferences. It does not mean submitting to whatever the patient wants. Patients, as consumers, are permitted to base medical decisions on their own idiosyncrasies, preconceptions, and knowledge; but they cannot necessarily demand that health care professionals help them pursue those decisions, particularly when the physician 
perceives that the decision poses risk to the patient or to his or her own integrity.

Medical treatment is not simply a matter of self-determination but of a joint decision between patient and physician regarding what best reflects the patient's goals of care and the physician's judgment as to the most appropriate way of achieving those goals. Both patient and physician are stakeholders in the care process. The assertion of patients' rights may subvert the negotiation, providing a trump card for patient choice and setting aside medical judgment for the sake of "respecting patient autonomy." Far from demonstrating respect for a patient's values and preferences, the technician-doctor need not even understand what the patient believes; rather the physician simply agrees to do whatever the patient asks. No relationship develops, and when the physician wishes to refuse a patient's demand for nonbeneficial, futile, or otherwise medically inappropriate treatment, no context for mutual negotiation based on trust exists. "When self-determination runs amok" [13] physicians may feel they are reduced to providing technical assistance to their patients.

Beyond the impact on the patient-physician relationship, the quest for rights to more and better health care, for increased control over medical information and decision making, and for legal means of redress for care gone wrong has obscured discussions about the goals of health care and priorities for use. A focus on paternalism and patients' rights highlights the difficult balance among patient autonomy, beneficence, and clinician integrity but masks the role of distributive justice [14]. Ultimately, considerations of justice may mean that society must constrain and prioritize the medical choices available to individuals - those a physician may offer and those a patient may seek-to promote more equitable distribution for all.

The call for rights finds strength in a culture that pushes the limits of medical technology to the point of denying the inevitability of death, pays too little attention to the prudent and fair access to and distribution of health care resources, seeks to assign blame for all nature of misfortune, and worries about increasing infringements on personal information. Until we address these characteristics, we cannot begin to make the really difficult choices: Whose health? Which diseases? What technology? Focusing on individual rights of either patients or physicians may distract us from these broader societal choices.

Yet, none of this discussion is intended to suggest that patients do not or should not have rights. Certainly patients must have a role in decisions about their health and lives. Unchecked physician paternalism rarely can be justified, but neither can unlimited patient autonomy. This discussion serves merely as a caution against the law of unintended consequences and a reminder that personal values do not exist in a vacuum. The difficult task of balancing autonomy and beneficence remains, but these are only 2 among a number of values that health care must demonstrate.

\section{References}

1. Opinion 10.01 Fundamental Elements of the Patient-Physician Relationship. Code of Medical Ethics 2008-2009 Edition. Chicago, IL: American Medical Association; 2008:341-347.

2. Katz J. Silent World of Doctor and Patient. New York: The Free Press; 1984:xiv. Google Scholar

3. The SUPPORT Principal Investigators. A controlled trial to improve care for seriously ill hospitalized patients: the study to understand prognoses and preferences for outcomes and risks of treatments (SUPPORT). JAMA. 1995; 274:1591-1598. View Article PubMed Google Scholar

4. Dying well in the hospital: the lessons of SUPPORT,The Hastings Center Report: special supplement . November-December 1995:S1-S36.

5. Cassell E. The Place of Humanities in Medicine. New York: Institute of Society, Ethics, and the Life Sciences; 1984:16.

Google Scholar

6. Correia NG. Adverse events: reducing the risk of litigation. Cleve Clin J Med. January 2002;69:15-17, 23-24. PubMed Google Scholar 
7. Hebert PC, Levin AV, Robertson G. Bioethics for clinicians: 23. Disclosure of medical error. CMAJ. 2001;164:509-513.

PubMed Google Scholar

8. Glendon MA. Rights Talk: The Impoverishment of Political Discourse. New York: The Free Press; 1991:x. Google Scholar

9. Childress JF, Siegler M. Metaphors and models of doctor-patient relationships: their implications for autonomy. Theor Med. February 1984; 5:17-30.

View Article PubMed Google Scholar

10. Emanuel EJ, Emanuel LL. Four models of the physician-patient relationship. JAMA. 1992;267:2221-2226. View Article PubMed Google Scholar

11. Beauchamp TL, Childress JF. Principles of Biomedical Ethics. 5th ed. New York: Oxford University Press. 2001;39.

Google Scholar

12. The Hastings Center. Guidelines on the Termination of Life-Sustaining Treatment and the Care of the Dying. Briarcliff Manor, NY: The Hastings Center;1987:6-8.

Google Scholar

13. Callahan D. When self-determination runs amok. The Hastings Center Report. March-April 1992;22:52.

PubMed Google Scholar

14. Beauchamp TL, Childress JF. Justice. In: Principles of Biomedical Ethics. 5th ed. New York: Oxford University Press. 2001;225-272.

Google Scholar

Felicia Cohn, $\mathrm{PhD}$, is director of medical ethics at the University of California, Irvine, College of Medicine. She teaches and develops the ethics curriculum for the College of Medicine, and conducts research on ethical issues. Current projects include a study on the impact of ethics consultation in the ICU, development of an ethics liaison program, and patient safety education.

The viewpoints expressed on this site are those of the authors and do not necessarily reflect the views and policies of the AMA.

(C) 2004 American Medical Association. All Rights Reserved. 